\title{
Rancang Bangun Aplikasi Penggajian Menggunakan Hybrid Mobile Programming di CV Agung Glass
}

\author{
Dian Kasoni $^{1}$, Catur Siswoko ${ }^{2}$ Liesnaningsih $^{3}$, Rohmat Taufiq ${ }^{4}$ \\ 1,2Department, STMIK Antar Bangsa, Kawasan Bisnis CBD Ciledug Blok A5 No.29-36, Jalan \\ HOS Cokroaminoto, KecamatanKarang Tengah, Kota Tangerang, Banten 15157 \\ 3,4 Department, University of Muhammadiyah Tangerang, Jalan Perintis Kemerdekaan I Babakan \\ No.33, RT.007/RW.003, Cikokol, Kecamatan Tangerang, Kota Tangerang, Banten 15118 \\ e-mail: ${ }^{1}$ dhekalearning@ gmail.com, ${ }^{2}$ cathdomes@gmail.com, ${ }^{3}$ liesnaningsih@ft-umt.ac.id, \\ ${ }^{4}$ rohmat.taufiq@umt.ac.id
}

Submitted Date: September $08^{\text {th }}, 2020$

Revised Date: September $28^{\text {th }}$, 2020
Reviewed Date: September $22^{\text {nd }}, 2020$

Accepted Date: September $30^{\text {th }}, 2020$

\begin{abstract}
Salary is remuneration received by workers in the form of money based on a certain time. Processing employee salary data is very important for companies to appreciate their employees who are already working. The payroll process for employees at CV Agung Glass currently uses Ms. Excel, this causes several errors that often occur in the salary calculation process. As a growing company, CV Agung Glass needs a data processing application that can assist in processing employee payroll data quickly, precisely, and thoroughly. The method used in this payroll system is the iteration method, which is an application design method by sequencing the steps in designing the application, then repeating it if there are errors or developments for the application. The programming language used to make this payroll application is hybrid programming for mobile by combining two different programming languages, namely mobile programming using Android Studio and web programming using PHP.
\end{abstract}

Keywords: Payroll System; Hybrid Mobile Programming; Iteration Method

\section{Abstrak}

Gaji merupakan balas jasa yang diterima pekerja dalam bentuk uang berdasarkan waktu tertentu. Pengolahan data gaji karyawan menjadi sangat penting bagi perusahaan untuk menghargai para karyawannya yang sudah bekerja. Proses penggajian karyawan pada CV Agung Glass saat ini menggunakan Ms.Excel. Hal ini menyebabkan beberapa kesalahan yang sering terjadi dalam proses penghitungan gaji. Sebagai Perusahaan yang sedang berkembang, CV Agung Glass membutuhkan suatu aplikasi pengolahan data yang dapat membantu dalam mengolah data penggajian karyawan dengan cepat, tepat, dan teliti. Metode yang digunakan dalam sistem penggajian ini adalah metode iterasi, yaitu suatu metode perancangan aplikasi dengan mengurutkan langkah-langkah dalam merancang aplikasi, kemudian melakukan pengulangan apabila ada kesalahan ataupun pengembangan untuk aplikasi. Bahasa pemrograman yang digunakan untuk membuat aplikasi penggajian ini adalah hybrid programming untuk mobile dengan menggabungkan dua bahasa pemrograman yang berbeda yaitu mobile programming dengan menggunakan Android Studio dan web programming dengan menggunakan PHP.

Kata Kunci: Sistem Penggajian; Hybrid Mobile Programming; Metode Iterasi

\section{Pendahuluan}

Suatu perusahaan membutuhkan suatu sistem yang dapat membantu pekerjaan karyawannya. Pekerjaan yang dapat dilakukan dengan mudah dan cepat tentu akan meminimalisir waktu dalam mengerjakan 
pekerjaan tersebut, hal itu tentu akan memberikan keuntungan bagi perusahaan. Sebaliknya, suatu pekerjaan yang masih dilakukan secara manual tentu akan membutuhkan waktu yang lama. Perusahaan yang ingin berkembang tentu harus memiliki keunggulan yang kompetitif. Sistem informasi yang terus berkembang menjadi tantangan bagi perusahaan untuk memberikan pelayanan terbaik bagi stakeholdermaupun karyawannya. Suatu sistem yang dapat diakses dimana saja dengan menggunakan mobile device sangat diperlukan untuk menunjang pekerjaan yang harus dikerjakan di luar kantor seperti pengerjaan suatu proyek. Dengan pengembangan sistem informasi berbasis web dapat memudahkan pengguna dalam melakukan kegiatannya (Taufiq, 2020). Namun sebelum proses perancangan terlebih dahulu dilakukan analisis agar memudahkan dalam proses pengembangan (Pertiwi dan Taufiq, 2020)

CV Agung Glass merupakan perusahaan yang bergerak dibidang penjualan, pembuatan, dan pemasangan kaca, dan aluminium. Pada perusahaan tersebut semua pekerjaan masih dilakukan secara manual, mulai dari pencatatan data karyawan, input proyek, absensi karyawan, serta perhitungan gaji karyawan. Hal tersebut memberikan dampak sulitnya menemukan data karyawan, proyek-proyek terdahulu, dan proses perhitungan gaji yang memerlukan waktu yang lama, karena harus melihat satu persatu arsip proyek yang dikerjakan karyawan sehingga membuat pekerjaan menjadi tidak efisien. Berdasarkan hal tersebut, maka dibutuhkan sebuah aplikasi mobile yang dapat mengolah data karyawan, data proyek, absensi karyawan, dan perhitungan gaji serta dapat diakses dimana saja dan kapan saja.Dengan laporan yang terintegrasi, pengolahan data lebih cepat dan minim kesalahan sehingga memudahkan proses pengambilan keputusan (Liesnaningsih, 2019).

Tujuan dari penelitian ini yaitu membuat suatu sistem penggajian karyawan pada CV Agung Glass yang dapat diakses secara mobile; membuat sistem yang dapat mengelola data karyawan dan data proyek; serta membuat sistem absensi karyawan berbasis mobile sehingga dengan adanya sistem penggajian tersebut pekerjaan dapat menjadi lebih efisien.

\section{Tinjauan Pustaka}

2.1. Aplikasi Penggajian berbasis Web
Aplikasi merupakan program siap pakai yang dapat digunakan untuk menjalankan perintah-perintah dari pengguna dengan tujuan mendapatkan hasil yang lebih akurat Abdurahman dan Riswayah (2014) dalam (Widarma dan Rahayu, 2017). Pemrograman web secara umum terdiri atas web servers dan web browser. web servers merupakan komputerkomputer yang menaungi halaman web, sedangkan web browser merupakan suatu aplikasi yang digunakan oleh pengguna sebagai wadah untuk melihat halaman web tersebut. (Steven and Janet, 2013). Sebuah SPK berbasis web akan menyelesasikan permasalahan secara efektif dan optimal (Liesnaningsih. Taufiq, Destriana, dan Prayoga, 2020).

Beberapa aplikasi penggajian sudah diteliti diantaranya menurut (Moenir dan Yuliyanto, 2017) memberikan kesimpulan bahwa dengan adanya sistem informasi penggajian memudahkan perusahahaan memperolah data karyawan dengan cepat dan meminimalisir kesalahan. Selain itu menurut peneliti yang lain memiliki kelebihan untuk mengetahui laporan gaji secara tepat pada saat dibutuhkan (Mayasari, 2015).

\subsection{Aplikasi Hybrid}

Pada intinya aplikasi berbasis hybrid menggabungkan aplikasi mobile jenis native dengan aplikasi mobile jenis web dan dikemas menjadi 1 package, kemudian dipasang di device kita atau bisa juga langsung diunggah ke toko aplikasi mobile sesuai dengan platform-nya, seperti Google Playstore untuk android ataupun App Store untuk IOS. Sama halnya aplikasi berbasis native, aplikasi berbasis hybrid ini membutuhkan proses instalasi. (Khanderparker, 2015)

Aplikasi berbasis hybrid pada sistem informasi mampu menggabungkan kedua sisi program yang dihubungkan dengan menggunakan Resful Web Service (Pradana dan Waspada, 2019). Aplikasi berbasis hybrid memiliki manfaat dalam bidang penggajian lebih memberikan kemudahan jika terjadi perubahan data karyawan kontrak maupun tetap (Benny, 2019).

\section{Hasil dan Pembahasan}

\subsection{Analisa Kebutuhan}

Dalam membuat suatu aplikasi diperlukan berbagai hal yang harus dimiliki oleh seorang 
pengembang aplikasi sesuai dengan aplikasi yang dibuat. baik itu dari segi kebutuhan software oleh seorang pengembang maupun kebutuhan dari segi hardware. Seorang pengembang aplikasi juga harus memperhitungkan kebutuhankebutuhan yang harus dipenuhi oleh user dalam menggunakan aplikasinya. Selain menganalisa kebutuhan bagi aplikasi yang akan dijalankan, seorang pengembang aplikasi juga harus memperhitungkan total biaya dan waktu yang akan dipakai dalam membangun maupun mengembangkan aplikasinya. suatu analisa kebutuhan yang baik akan mempermudah pengembang aplikasi dalam membangun dan merancang aplikasinya.

Adapun spesifikasi perangkat keras yang dibutuhkan untuk membangun aplikasi ini adalah:

1. Processor AMD Phenom II X4 965.

2. AMD Radeon HD 5670.

3. 8GB DDR3 RAM.

4. 14" Layar LCD.

5. 500GB Harddisk.

6. Keyboard.

7. Mouse.

8. Xiaomi Redmi 5A sebagai emulator untuk aplikasi android.

9. Modem sebagai penunjang jaringan internet.

Untuk membangun aplikasi ini dibutuhkan beberapa perangkat lunak yang harus digunakan, yaitu:

1. Android Studio versi 3.4.2.

2. XAMPP versi 3.2.2.

3. FileZilla sebagai penunjang FTP kedalam server web.

\subsection{Entity Relationship Diagram}

ERD menggambarkan entity-relationship model yang merupakan gabungan konsep entitas, atribut, dan hubungan antar entitas, dan entitas dalam ERD merepresentasikan sesuatu (things) atau benda dalam dunia nyata.(Adi \& Kristin, 2014)

Berikut merupakan gambar Entity Relationship Diagram dari database yang ada pada aplikasi :

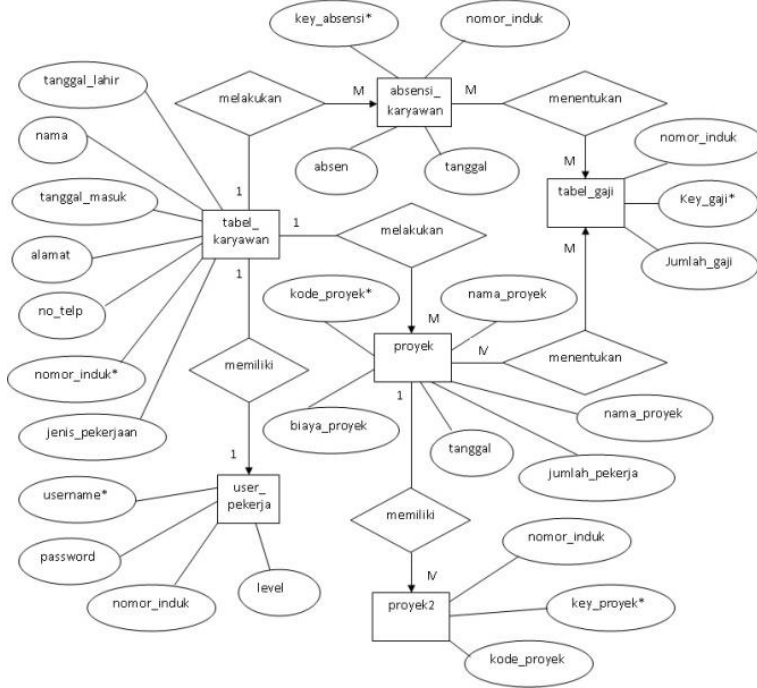

Gambar 1. Entity Relationship Diagram

\subsection{Model Perancangan Aplikasi}

Pada aplikasi ini model perancangan aplikasi yang dipakai adalah dengan menggunakan metode iterasi. Metode iterasi merupakan suatu metode perancangan aplikasi dengan mengurutkan langkah-langkah dalam merancang aplikasi, kemudian melakukan pengulangan apabila ada kesalahan ataupun pengembangan untuk aplikasi.

Berikut merupakan gambar dari metode perancangan aplikasi ini dengan menggunakan metode iterasi :

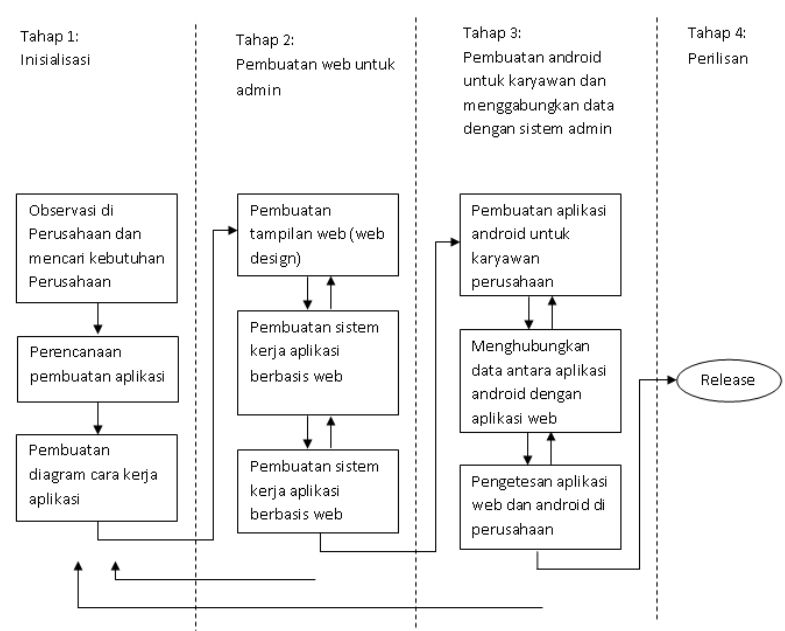

Gambar 2. Metode Perancangan Aplikasi

Pada metode iterasi dibagi menjadi empat tahap, berikut penjelasannya:

1. Tahap Inisialisasi

a. Observasi 
Pada tahap ini penulis melakukan oberservasi di perusahan tempat penulis melakukan riset untuk mencari permasalahan perusahaan serta mencari kebutuhan yang diperlukan oleh perusahaan tersebut.

b. Perencanaan pembuatan aplikasi

Pada tahap ini penulis membuat rancangan untuk pembuatan aplikasi agar sesuai dengan kebutuhan dari perusahaan.

c. Pembuatan diagram cara kerja aplikasi Pada tahap ini penulis membuat cara kerja aplikasi yang akan dibuat dengan cara membuat use case diagram.

2. Tahap Pembuatan Web Untuk Admin

a. Pembuatan tampilan web

Pada tahap ini penulis membuat tampilan web untuk admin sesuai dengan rencana pembuatan aplikasi.

b. Pembuatan sistem kerja aplikasi berbasis web

Pada tahap ini penulis membuat sistem aplikasi yang akan bekerja sesuai dengan rancangan pembuatan aplikasi.

c. Pengetesan aplikasi web di perusahaan untuk admin

Pada tahap ini penulis melakukan uji coba penggunaan aplikasi web pada laptop manager keuangan yang ada pada perusahaan dan melihat apakah aplikasi web tersebut dapat berjalan sesuai dengan rancangan aplikasi pada laptop manager keuangan. Apabila aplikasi web tersebut tidak sesuai dengan rancangan atau ada penambahan dari pihak perusahaan, penulis akan mengatur rancangan dan kembali ke tahap inisialisasi.

3. Tahap Pembuatan Android Untuk Karyawan dan Menggabungkan Data dengan Sistem Admin.

a. Pembuatan aplikasi android

Pada tahap ini penulis membuat aplikasi berbasis android dengan menggunakan android studio untuk karyawan perusahaan.

b. Menghubungkan database antara aplikasi web dan android

Pada tahap ini penulis menghubungkan database pada aplikasi web dan android, dimana karyawan dapat mengakses sebagian data dari database aplikasi web. c. Pengetesan aplikasi web dan android di perusahaan

Pada tahap ini penulis melakukan uji coba penggunaan aplikasi web dan android pada perusahaan, apakah sudah sesuai dengan rancangan pembuatan aplikasi atau belum. apabila tidak sesuai dengan rancangan pembuatan aplikasi, maka penulis akan melakukan tahap pertama dan apabila aplikasi tersebut tidak berjalan dengan baik maka penulis akan melakukan tahap kedua kembali.

4. Perilisan

Pada tahap ini penulis menyebarkan aplikasi android kepada setiap karyawan perusahaan, serta mengambil data-data perusahaan agar data pada sistem database pada aplikasi dapat sesuai dengan kenyataan yang terjadi di lapangan.

\section{Rancangan Tampilan}

\subsection{Tampilan Menu Login}

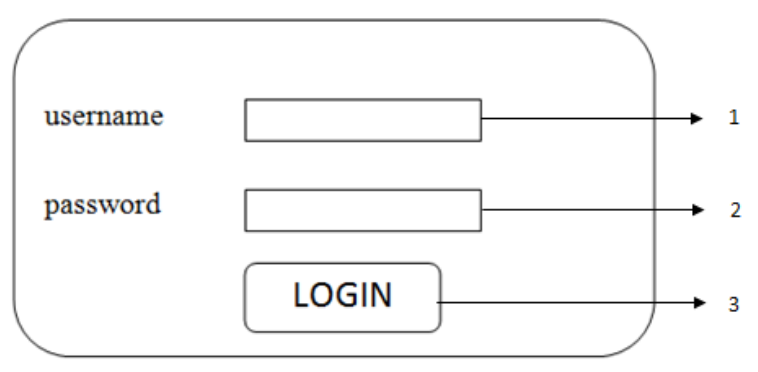

Gambar 3. Tampilan Login

Keterangan:

1. Text field username.

2. Text field password.

3. Tombol Login.

Cara kerja sistem login adalah dengan cara memasukkan username dan password, kemudian sistem akan mengecek apakah username dan password yang dimasukkan sesuai dengan database, jika sesuai maka aplikasi akan berpindah ke halaman utama sesuai dengan level akun yaitu, direktur, admin dan user. jika tidak sesuai maka aplikasi akan tetap di halaman login. 


\subsection{Tampilan Menu Utama}

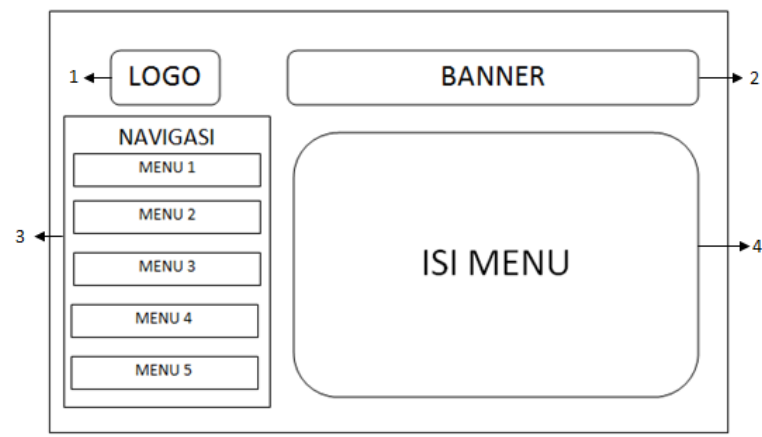

Gambar 4. Tampilan Menu Utama

Keterangan:

1. Logo: merupakan logo dari perusahaan

2. Banner: berisi nama perusahaan dan nama judul program

3. Navigasi: merupakan tombol untuk memasuki sub-menu yang ada didalam aplikasi.

4. Isi Menu: merupakan tampilan isi sesuai dari menu yang dipilih.

Pada menu utama terdapat 5 Menu yang dapat dipilih yaitu :

1. Input Proyek Baru, berfungsi untuk memasukkan proyek baru ke dalam sistem database.

2. Input Data Karyawan, berfungsi untuk memasukkan data karyawan baru ke dalam sistem database.

3. Lihat Data Proyek, berfungsi untuk melihat, merubah, menghapus, dan mencari seluruh data proyek yang ada pada sistem web.

4. Lihat Data Karyawan, berfungsi untuk melihat, merubah, menghapus dan mencari seluruh data karyawan yang ada pada sistem web.

5. Gaji Karyawan, berfungsi untuk memasukkan gaji setiap karyawan, halaman ini dilengkapi dengan seluruh histori absensi, histori gaji, dan histori proyek setiap karyawan.

\subsection{Tampilan Input Proyek Baru}

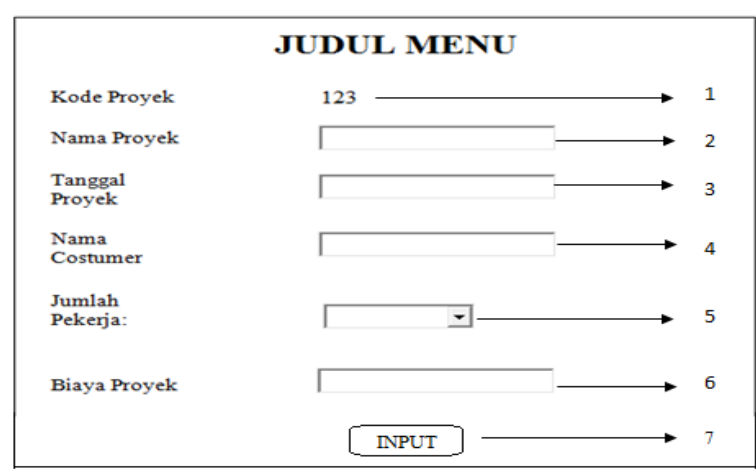

Gambar 5. Tampilan Input Proyek Baru

Keterangan:

1. Kode proyek: merupakan kode setiap proyek yang berbeda, akan muncul secara otomatis.

2. Nama proyek: merupakan nama dari proyek yang akan di masukkan.

3. Tanggal proyek: merupakan tanggal pertama proyek dikerjakan.

4. Nama costumer: merupakan nama pelanggan dari proyek tersebut.

5. Jumlah pekerja: merupakan jumlah pekerja dalam proyek tersebut.

6. Biaya proyek: merupakan biaya yang dikeluarkan oleh costumer untuk menyelesaikan proyek tersebut.

7. Input: merupakan tombol untuk memasukkan data yang sudah di input kedalam database.

\subsection{Tampilan Input Karyawan Baru}

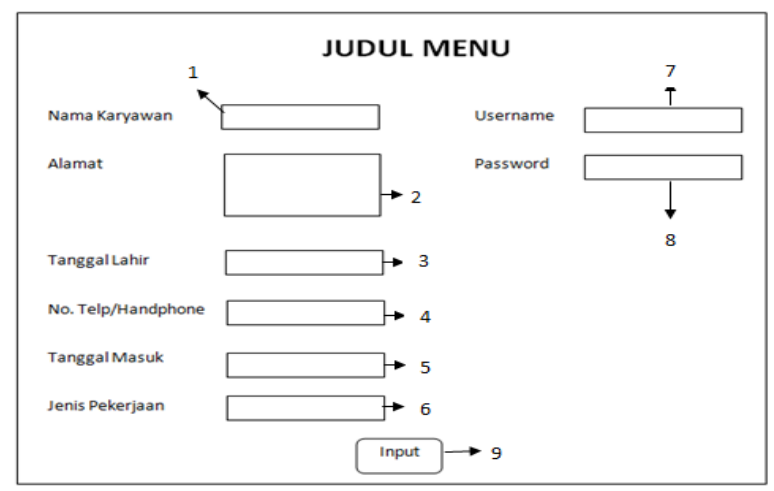

Gambar 6. Tampilan Input Karyawan Baru

Keterangan:

1. Nama Karyawan: merupakan nama karyawan.

2. Alamat: merupakan alamat dari karyawan.

3. Tanggal lahir: merupakan tanggal lahir karyawan. 
4. No Telp/Handphone: merupakan nomor telepon atau handphone dari karyawan

5. Tanggal masuk: merupakan tanggal pertama kali karyawan bekerja.

6. Jenis pekerjaan: merupakan jenis pekerjaan karyawan, ada 4 jenis pekerjaan dalam perusahaan yaitu, office, pengerjaan bahan, pengerjaan lapangan dan distribusi.

7. Username: merupakan nama akun dari karyawan yang dapat dipakai pada saat melakukan login pada aplikasi karyawan.

8. Password: merupakan kata sandi untuk masuk ke dalam aplikasi karyawan.

9. Input: merupakan tombol untuk memasukkan data yang sudah di input kedalam database.

\subsection{Tampilan Lihat Data Proyek}

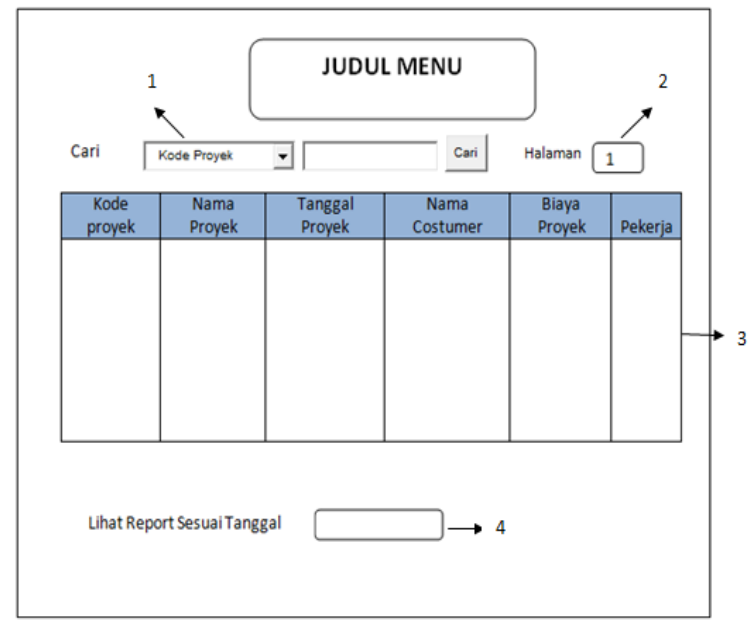

Gambar 7. Tampilan Lihat Data Proyek

Keterangan:

1. Pencarian proyek : mencari data proyek sesuai dengan kategori pencarian dan data pencarian.

2. Halaman : mengganti ke halaman selanjutnya, setiap halaman memiliki 7 data proyek.

3. Tabel proyek : merupakan tabel yang berisi data-data proyek yang sudah di masukkan sebelumnya.

\subsection{Tampilan Gaji Karyawan}

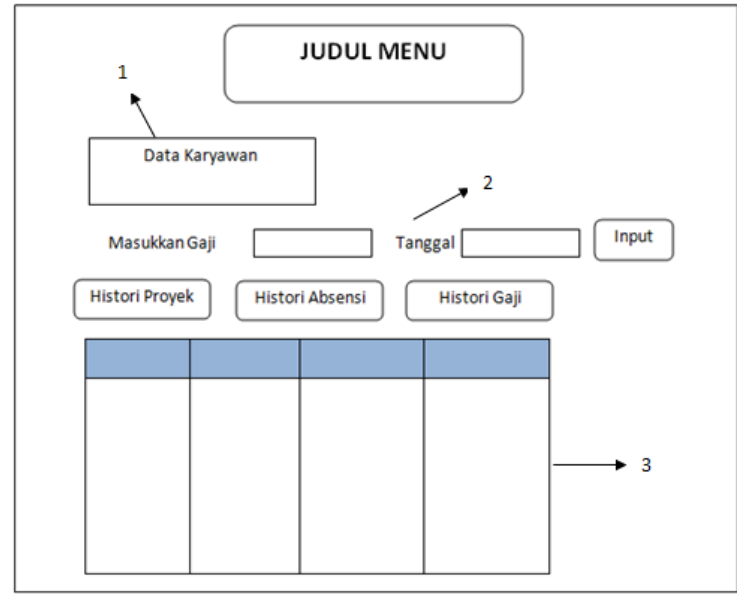

Gambar 8. Tampilan Gaji Karyawan

Keterangan:

1. Data Karyawan: berisi data karyawan sesuai dengan data karyawan yang dipilih.

2. Input gaji: mengganti ke halaman selanjutnya, setiap halaman memiliki 7 data karyawan.

3. Tabel pilihan: merupakan tabel yang berisi data-data histori proyek, absensi, serta histori gaji sesuai pilihan tombol pada menu. Tabel ini hanya memuat data sesuai dengan data karyawan.

4. Tanggal : pencarian data proyek sesuai dengan range tanggal tertentu untuk dijadikan laporan report, dan dapat langsung dicetak.

\subsection{Blackbox Testing}

Berikut pengujian aplikasi penggajian dengan menggunakan blackbox testing di $\mathrm{CV}$ Agung Glass:

Tabel 1. Pengujian Form Login

\begin{tabular}{|l|l|l|}
\hline No & $\begin{array}{l}\text { Skenario } \\
\text { Pengujian }\end{array}$ & Hasil Pengujian \\
\hline 1 & $\begin{array}{l}\text { User salah } \\
\text { mengisi } \\
\text { username dan } \\
\text { password }\end{array}$ & $\begin{array}{l}\text { Sistem akan } \\
\text { menampilkan pesan: } \\
\text { "Username/Password } \\
\text { SALAH!" }\end{array}$ \\
\hline 2 & $\begin{array}{l}\text { Admin mengisi } \\
\text { username dan } \\
\text { password }\end{array}$ & $\begin{array}{l}\text { Sistem akan } \\
\text { menampilkan } \\
\text { halaman admin }\end{array}$ \\
\hline 3 & $\begin{array}{l}\text { Direktur } \\
\text { mengisi } \\
\text { username dan }\end{array}$ & $\begin{array}{l}\text { Sistem akan } \\
\text { menampilkan } \\
\text { halaman direktur }\end{array}$ \\
\hline
\end{tabular}




\begin{tabular}{|l|l|l|}
\hline & $\begin{array}{l}\text { password } \\
\text { direktur }\end{array}$ & \\
\hline 4 & $\begin{array}{l}\text { Karyawan } \\
\text { mengisi } \\
\text { username dan } \\
\text { password } \\
\text { karyawan }\end{array}$ & $\begin{array}{l}\text { Sistem akan } \\
\text { menampilkan } \\
\text { halaman karyawan }\end{array}$ \\
\hline
\end{tabular}

Tabel 2. Pengujian Basis Data

\begin{tabular}{|c|c|c|}
\hline No & $\begin{array}{l}\text { Skenario } \\
\text { Pengujian }\end{array}$ & Hasil Pengujian \\
\hline 1 & $\begin{array}{l}\text { User mengisi data } \\
\text { proyek dan } \\
\text { menekan tombol } \\
\text { simpan }\end{array}$ & $\begin{array}{l}\text { Sistem menyimpan } \\
\text { data proyek ke } \\
\text { dalam table proyek } \\
\text { dan menampilkan } \\
\text { pesan: "Data telah } \\
\text { masuk" }\end{array}$ \\
\hline 2 & $\begin{array}{l}\text { User mengisi data } \\
\text { karyawan baru } \\
\text { dan menekan } \\
\text { tombol simpan }\end{array}$ & \begin{tabular}{ll}
\multicolumn{3}{l}{ Sistem menyimpan } \\
data karyawan ke \\
dalam table \\
karyawan dan \\
menampilkan \\
pesan: "Data telah \\
masuk"
\end{tabular} \\
\hline 3 & $\begin{array}{l}\text { User mengisi gaji } \\
\text { karyawan dan } \\
\text { menekan tombol } \\
\text { simpan }\end{array}$ & $\begin{array}{l}\text { Sistem menyimpan } \\
\text { data gaji karyawan } \\
\text { ke dalam tabel gaji } \\
\text { dan menampilkan } \\
\text { pesan: "Data telah } \\
\text { masuk" }\end{array}$ \\
\hline 4 & $\begin{array}{l}\text { Karyawan } \\
\text { melakukan } \\
\text { absensi dan } \\
\text { menekan tombol } \\
\text { simpan }\end{array}$ & $\begin{array}{l}\text { Sistem menyimpan } \\
\text { absensi karyawan } \\
\text { ke dalam tabel } \\
\text { absensi dan } \\
\text { menampilkan } \\
\text { pesan: "Absensi } \\
\text { sukses" }\end{array}$ \\
\hline 5 & \begin{tabular}{l}
\multicolumn{3}{l}{ Karyawan } \\
melakukan \\
absensi dua kali \\
pada hari yang \\
sama ran \\
menekan tombol \\
simpan
\end{tabular} & \begin{tabular}{|l|} 
Sistem \\
menampilkan \\
pesan: "Anda sudah \\
absensi hari ini"
\end{tabular} \\
\hline
\end{tabular}

\section{Kesimpulan}

Berdasarkan pembahasan hasil penelitian yang telah dibahas dalam bab sebelumnya, maka dapat disimpulkan sebagai berikut:

1. Dengan dibangunnya aplikasi sistem penggajian, diharapkan dapat memberikan kemudahan bagi karyawan untuk absensi, dan memberikan kemudahan dalam perhitungan gaji.

2. Menggunakan metode iterasi sebagai model perancangan aplikasi dengan langkahlangkah yang dilakukan secara urut, kemudian melakukan pengulangan saat terjadi kesalahan.

3. Aplikasi Sistem Penggajian dirancang menggunakan hybrid mobile programming dan teknik pengujian Black Box

\section{Daftar Pustaka}

Adi, S., \& Kristin, D. M. (2014). Strukturisasi Entity Relationship Diagram dan Data Flow Diagram Berbasis Business Event-Driven. ComTech, 26-34.

Benny. 2019. Perancangan Sistem Informasi Pengolahan Data Penggajian Karyawan Kontrak dan Karyawan Tetap Pada PT. Sinar Surya Kencana Abadi. Jurnal Ilmiah Core IT. Vol. 7 No. 1. Hal 209-221.

Khanderparkar, A. (2015) An Introduction to Hybrid Platform Mobile Application Development. Mumbai: Mukesh Patel School of Technology, Management and Engineering.

Liesnaningsih. Taufiq, R. Destriana, R. Prayoga, A. 2020. Sistem Pendukung Keputusan Penerima Beasiswa Berbasis WEB Menggunakan Metode Simple Additive Weighting (SAW) pada Pondok Pesantren Daarul Ahsan. Jurnal Informatika Universitas Pamulang. Vol 5 No 1. 2020.

Liesnaningsih. L, Oklawati. O dan Kasoni, D. 2019. Sistem Pendukung Keputusan Penilaian Karyawan Terbaik Menggunakan Metode SAW pada PT. Trans Retail Indonesia. Jurnal Teknik Informatika (JIKA) Universitas Muhammadiyah Tangearng, ISSN: 2549-0710. Hal.34-40.

Mayasari, MS. 2015. Analisis dan Perancangan Aplikasi Sistem Informasi Penggajian Karyawan pada PT. Aditya Buana Inter Sungailiat Bangka. Jurnal SIMETRIS, Vol. 6 No. 2 November 2015. Hal. 277-288.

Moenir A dan Yuliyanto, A. 2017. Peranangan Sistem Informasi Penggajian Berbasis Web dengan Metode Waterfall pada PT. Sinar Metrindo Perkasa (SIMETRI). JIUP Unpam. Vol. 2 No. 3, September 2017. Hal 127-137.

Pertiwi, DD dan Taufiq, R. 2002. Analisis dan Desain Sistem Informasi Pengolahan Nilai Siswa Avicena Rajek. JIKA Universitas Muhammadiyah Tangerang, Januari 2020 pp. 29-35.

Pradana, DI dan Waspada, I. 2019. Aplikasi Hybrid 
pada Sistem Informasi Penyewaan Buku. Jurnal SIMETRIS, Vol. 10 No. 1, 1 April 2019. Hal. $1-14$.

Steven dan Janet Valade. (2013) PHP, MySQL, JavaScript \& HTML5 All-in-One For Dummies. United States: For Dummies.

Taufiq, R. Magfiroh, DA. Yusuf, D dan Yulianti.2020. Sistem Informasi Pembayaran Sumbangan
Pembinaan Pendidikan (SPP) di SMK Avicena Rajeg. Jurnal Teknologi Sistem Informasi dan Aplikasi. Vol. 3 No. 1, Januari 2020. Hal 15-21. Widarma, A dan Rahayu, S. 2017. Perancangan Aplikasi Gaji Karyawan pada PT. PP London Sumatra Indonesia Tbk. Gunung Malayu Estate - Kabupaten Asahan. Jurnal Teknologi Informasi Vol. 1 No. 2. Desember 2017. Hal. 166-172. 